\title{
Assessment of exhaled carbon monoxide in exacerbations of chronic obstructive pulmonary disease
}

\author{
B Antus ${ }^{1,2}$, O Drozdovszky ${ }^{1}$, I Barta ${ }^{1}$ \\ ${ }^{1}$ Department of Pathophysiology, National Koranyi Institute of TB and Pulmonology, Budapest, Hungary \\ ${ }^{2}$ Department of Pulmonology, National Koranyi Institute of TB and Pulmonology, Budapest, Hungary
}

Received: March 3, 2015

Accepted: February 16, 2016

\begin{abstract}
Introduction: Exhaled carbon monoxide $(\mathrm{eCO})$ has been widely implicated as a pulmonary biomarker in respiratory diseases. The aim of this study was to investigate whether the treatment of patients with severe acute exacerbation of chronic obstructive pulmonary disease (AECOPD) could be aided by monitoring the changes in eCO. Methods: The levels of eCO along with routine clinical parameters were analyzed in 29 current smoker and 33 ex-smoker COPD patients, first at the time of hospital admission, and again at discharge following the standard treatment. Patients with AECOPD were also stratified according to sputum bacteria. Results: At exacerbation, the levels of eCO were increased in current smokers compared to ex-smokers $(6.0$ [2.0-9.5] versus $1.0[1.0-2.0] \mathrm{ppm}, p<0.001)$. Similarly, eCO levels were higher in smokers after treatment $(7.0[2.0-12.5]$ versus $1.0[1.0-2.0] \mathrm{ppm}, p<0.001)$. Treatment of AECOPD did not affect eCO concentrations. The levels of eCO were not statistically different between bacterial and non-bacterial AECOPD either. Investigating a subgroup of current smoker patients $(n=15)$, there was a significant correlation between the levels of eCO and blood carboxyhemoglobin concentrations both at exacerbation and discharge. No associations were found between eCO and lung function or blood gas parameters. Conclusion: Our results suggest that monitoring eCO during the treatment of AECOPD is of limited clinical value.
\end{abstract}

Keywords: COPD, bacteria, inflammation, monitoring, non-invasive, smoking

\section{Introduction}

Acute exacerbations of chronic obstructive pulmonary disease (AECOPD) are associated with an increased inflammation and oxidative stress (16). Exhaled breath analysis has enormous potential as an easy non-invasive mean of monitoring these processes in the airways (11).

One of the simple gases present in the exhaled breath that has been suggested to reflect ongoing oxidative stress and/or airway inflammation is carbon monoxide $(\mathrm{CO})(9,25)$. The measurement of exhaled $\mathrm{CO}(\mathrm{eCO})$ is a brief non-invasive procedure that provides immediate results, and is most commonly measured with electrochemical technology.

Increased concentration of eCO has been demonstrated in several inflammatory lung diseases including asthma (12), bronchiectasis (13), and cystic fibrosis (CF) (21). Several recent studies have reported the elevated levels of eCO in COPD as well $(18,20)$. However, eCO levels may also be elevated in healthy smokers due to the high $\mathrm{CO}$ content of cigarette

Corresponding author: Balazs Antus, MD, $\mathrm{PhD}$

Department of Pathophysiology, National Korányi Institute of TB and Pulmonology

Pihenô út 1, H-1121 Budapest, Hungary

Phone: +36 1 3913309; Fax: +36 1 2007060; E-mail: antusb@hotmail.com 
smoke $(6,7)$. Nevertheless, eCO concentrations are also increased in ex-smokers with COPD that may be the result of enhanced oxidative stress in the lungs (18).

In addition to these findings, the potential application of eCO for monitoring the effectiveness of anti-inflammatory therapeutics in patients with airway viral $(5,29)$ and/or bacterial (19) infections has also been suggested. In some animal models, systemic bacterial infection was also associated with an increased $\mathrm{CO}$ concentration in exhaled breath (3).

Only a few studies have investigated the changes in eCO levels in patients with AECOPD, and it is unclear whether common treatment with corticosteroids and bronchodilators modifies eCO during recovery. Moreover, it is unknown whether eCO measurement may assist in the selection of patients who would probably have a bacterial AECOPD. It is well established that bacterial infections play a pivotal role in the pathogenesis of AECOPD (4), and predicting bacteriological origin of an exacerbation might be of high clinical importance.

Therefore, this longitudinal study was undertaken to determine whether eCO concentrations are modified along with recovery as a result of treatment in patients with severe AECOPD. In addition, the levels of eCO were analyzed in relation with the results of conventional sputum bacterial culture.

\section{Materials and Methods}

Study subjects

Patients hospitalized with AECOPD were recruited for the study. Inclusion and exclusion criteria are summarized in Fig. 1. Exacerbation was defined as increased dyspnea, cough, or sputum expectoration (quality or quantity) that led the subject to seek medical attention, as

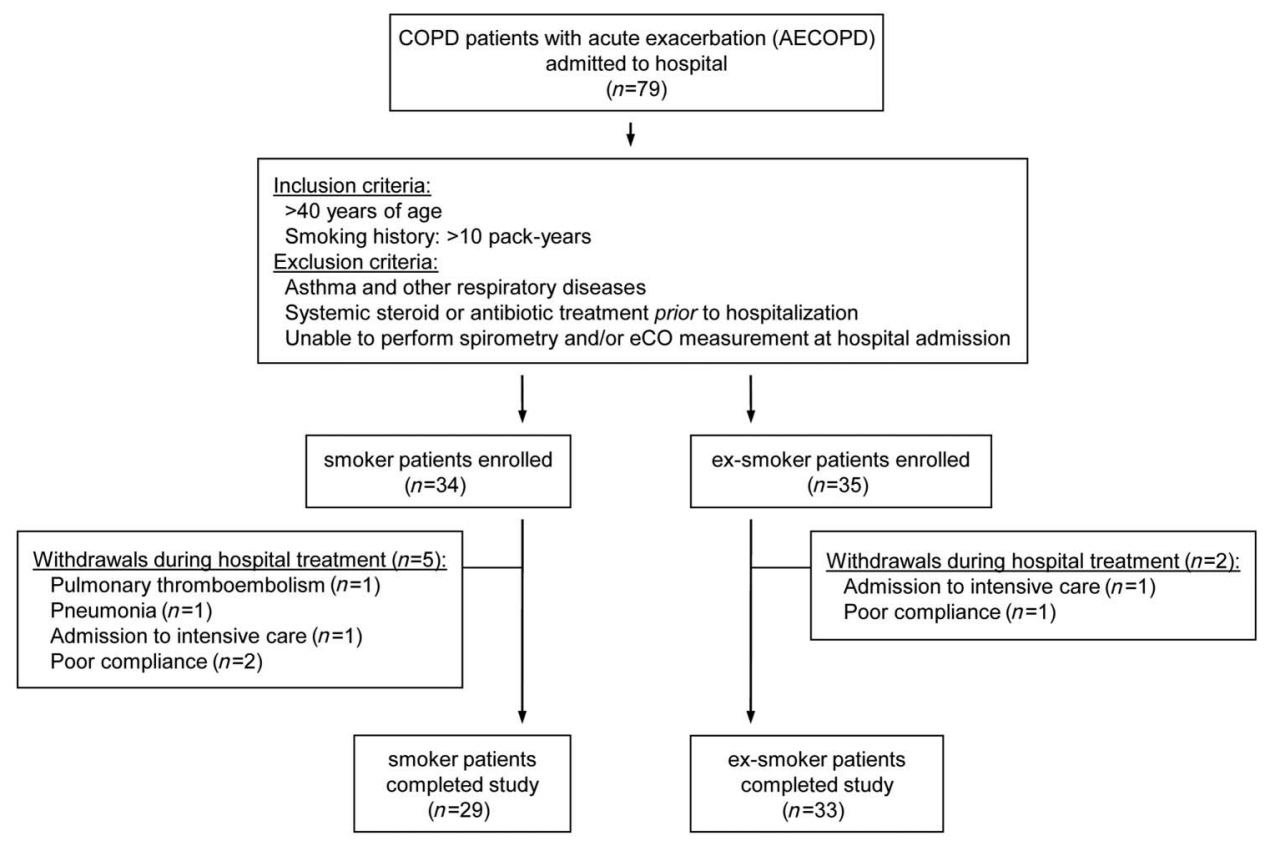

Fig. 1. Flowchart showing the study profile. COPD: chronic obstructive pulmonary disease 
specified in international guidelines (23). The research protocol was approved by the local ethics committee, and all the subjects gave written informed consent to participate in the study.

\section{Study design}

The levels of eCO, blood gases, and lung function parameters were measured at two time points: first at hospital admission of the patients, and again on the day of discharge following the treatment. White blood cell (WBC) count and C-reactive protein (CRP) values were measured in venous blood samples at hospital admission. In addition, in the subgroups of smoker $(n=15)$ and ex-smoker $(n=19)$ patients, the levels of carboxyhemoglobin $(\mathrm{HbCO})$ in arterialized capillary blood taken from the ears were determined using a blood gas analyzer both at exacerbation and after treatment. Measurements at exacerbations were performed before treatment in all patients. Lung function and blood gas parameters were determined, as previously described (2).

\section{Sputum bacterial culture}

At hospital admission, sputum was collected upon spontaneous expectoration in sterile vials from all patients. Samples were processed locally for Gram stain and routine bacteriological culture. Identification was performed on all potentially pathogenic microorganisms (PPMs) including Streptococcus pneumoniae, Haemophilus influenzae, Moraxella catarrhalis, and Pseudomonas aeruginosa according to standardized protocols (10). Since the significance of other bacteria such as Staphylococcus aureus and Haemophilus parainfluenzae is debated (20), these agents were not considered as PPMs. Similarly, other bacterial species in sputum were classified as normal flora, in line with other studies (27).

\section{Measurement of eCO}

The levels of eCO were measured using a portable $\mathrm{CO}$ monitor (Smokerlyzer Micro, Bedfont Scientific Ltd., Kent, UK). The results were given in parts per million (ppm). According to the manufacturer's specifications, the sensitivity of the sensor is $1 \mathrm{ppm}$, while the accuracy of the device is $\pm 2 \mathrm{ppm}$.

\section{Statistical analysis}

Data are presented as mean \pm SEM or median with interquartile range as appropriate. Data distribution was analyzed by the Kolmogorov-Smirnov test. eCO and $\mathrm{HbCO}$ levels between the current smoker and ex-smoker patients or bacterial and non-bacterial AECOPD were analyzed by the Mann-Whitney test. Paired Student's $t$-test (parametric data) and the Wilcoxon signed-rank test (non-parametric data) were used to compare the measurements at the time of hospital admission and the measurements at discharge. Correlation coefficients were calculated by Spearman's method. Power calculation was performed with $\alpha=0.05$ and 0.78 effect size. The calculations were performed by GraphPad Prism 4.0 (GraphPad Software Inc., San Diego, CA, USA) and G*Power 3.1.1 (G*Power Software Inc., Kiel, Germany) software packages. A $p$-value $<0.05$ was considered significant.

\section{Results}

About 79 patients with AECOPD were screened; 69 fulfilled inclusion criteria (Fig. 1). During hospital treatment, seven patients were excluded. Demographic and clinical data of the 29 smoker and 33 ex-smoker patients who completed the study are presented in Table I. 
Table I. Demographic and clinical characteristics of study subjects

\begin{tabular}{|c|c|c|c|c|}
\hline & \multicolumn{2}{|c|}{ Smoker COPD } & \multicolumn{2}{|c|}{ Ex-smoker COPD } \\
\hline Subjects $(n)$ & \multicolumn{2}{|c|}{29} & \multicolumn{2}{|c|}{33} \\
\hline Sex (male/female, $n$ ) & \multicolumn{2}{|c|}{$15 / 14$} & \multicolumn{2}{|c|}{$18 / 15$} \\
\hline Age (years) & \multicolumn{2}{|c|}{$62.3 \pm 1.8$} & \multicolumn{2}{|c|}{$68.3 \pm 1.9$} \\
\hline Smoking (pack-years) & \multicolumn{2}{|c|}{$40.2 \pm 4.4$} & \multicolumn{2}{|c|}{$38.0 \pm 3.6$} \\
\hline \multicolumn{5}{|l|}{ GOLD stages $(n, \%)$} \\
\hline $\mathrm{I}$ & \multicolumn{2}{|c|}{$5(17)$} & \multicolumn{2}{|c|}{$7(22)$} \\
\hline II & \multicolumn{2}{|c|}{$14(48)$} & \multicolumn{2}{|c|}{$12(36)$} \\
\hline III & \multicolumn{2}{|c|}{$8(28)$} & \multicolumn{2}{|c|}{$12(36)$} \\
\hline IV & \multicolumn{2}{|c|}{$2(7)$} & \multicolumn{2}{|c|}{$2(6)$} \\
\hline \multicolumn{5}{|c|}{ Pulmonary medication $^{\mathrm{c}}(n, \%)$} \\
\hline ICS & \multicolumn{2}{|c|}{$22(76)$} & \multicolumn{2}{|c|}{$21(64)$} \\
\hline LABA & \multicolumn{2}{|c|}{$24(83)$} & \multicolumn{2}{|c|}{$24(73)$} \\
\hline \multirow[t]{2}{*}{ LAMA } & \multicolumn{2}{|c|}{$20(69)$} & \multicolumn{2}{|c|}{$23(70)$} \\
\hline & At admission & $\begin{array}{c}\text { After } \\
\text { treatment }\end{array}$ & At admission & $\begin{array}{c}\text { After } \\
\text { treatment }\end{array}$ \\
\hline FVC (L) & $2.1 \pm 0.1$ & $2.3 \pm 0.1 * *$ & $2.0 \pm 0.1$ & $2.2 \pm 0.2 *$ \\
\hline FVC $(\%$ predicted $)$ & $69.6 \pm 3.8$ & $78.0 \pm 4.4^{* *}$ & $72.2 \pm 3.6$ & $83.7 \pm 5.1^{*}$ \\
\hline $\mathrm{FEV}_{1}(\mathrm{~L})$ & $1.0 \pm 0.1$ & $1.2 \pm 0.1^{* *}$ & $0.9 \pm 0.1$ & $1.2 \pm 0.1 * * *$ \\
\hline $\mathrm{FEV}_{1}(\%$ predicted $)$ & $42.9 \pm 3.1$ & $48.8 \pm 3.5^{* *}$ & $43.8 \pm 4.4$ & $55.4 \pm 3.6^{* * *}$ \\
\hline $\mathrm{FEV}_{1} / \mathrm{FVC}(\%)$ & $50.3 \pm 2.9$ & $50.4 \pm 3.0$ & $48.3 \pm 3.5$ & $55.4 \pm 3.6^{* * *}$ \\
\hline $\mathrm{PaO}_{2}(\mathrm{kPa})$ & $7.5 \pm 0.4$ & $7.6 \pm 0.3$ & $7.1 \pm 0.2$ & $7.9 \pm 0.2 * *$ \\
\hline $\mathrm{PaCO}_{2}(\mathrm{kPa})$ & $5.4 \pm 0.3$ & $5.5 \pm 0.2$ & $5.5 \pm 1.2$ & $6.1 \pm 0.3$ \\
\hline $\operatorname{HbCO}(\%)^{\mathrm{ab}}$ & $3.0(2.2-3.3)$ & $2.9(2.5-3.4)$ & $2.7(1.6-2.8)^{* * * *}$ & $2.3(1.7-2.9)^{* * * *}$ \\
\hline
\end{tabular}

Data are presented as mean \pm SEM unless stated otherwise. GOLD: global initiative for chronic obstructive lung disease, FVC: forced vital capacity, $\mathrm{FEV}_{1}$ : forced expiratory volume in $1 \mathrm{~s}, \mathrm{PaCO}_{2}$ : arterial carbon dioxide tension, $\mathrm{PaO}_{2}$ : arterial oxygen tension, $\mathrm{HbCO}$ : carboxyhemoglobin, ICS: inhaled corticosteroid, LABA: long-acting $\beta_{2}$-agonist, and LAMA: long-acting muscarinic antagonist. ${ }^{\mathrm{a}}$ Median (interquartile ranges), ${ }^{\mathrm{b}}$ obtained from 15 smoker and 19 ex-smoker patients, ${ }^{c}$ before hospital admission. ${ }^{*} p<0.05, * * p<0.01$ or $* * * p<0.001$ after treatment versus admission, $* * * * p<0.05$ ex-smoker versus smoker patients.

\section{Treatment of AECOPD}

Patients with AECOPD showed the disturbance of lung function, hypoxia, and increased systemic inflammatory markers (WBC: $14.2 \pm 2.4 \times 10^{9} / \mathrm{L}$ and CRP: $44.1 \pm 8.8 \mathrm{mg} / \mathrm{L}$ ). Exacerbations were treated with systemic (i.v. or oral) glucocorticoids and bronchodilators 


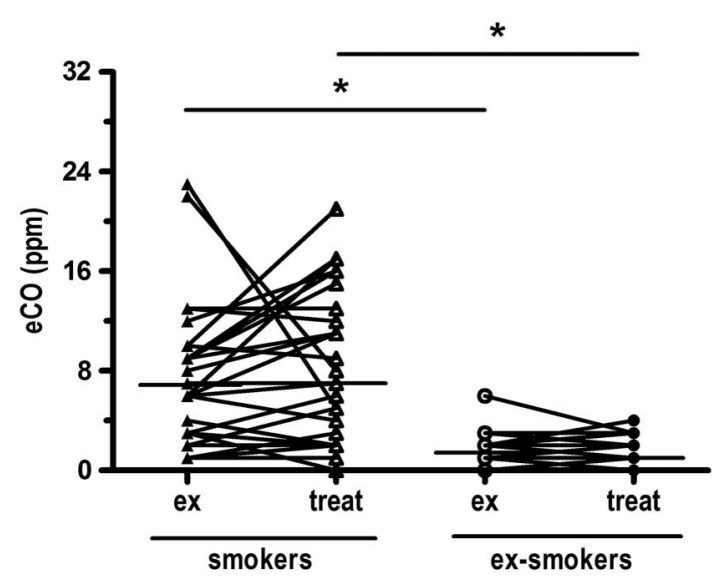

Fig. 2. Levels of exhaled carbon monoxide (eCO) in smoker $(n=29)$ and ex-smoker $(n=33)$ COPD patients at the time of an acute exacerbation (ex) and after hospital treatment (treat). Horizontal bars represent the median values. ppm: parts per million. ${ }^{*} p<0.001$ ex-smokers versus smokers

(anticholinergics and/or $\beta_{2}$-agonists) in all cases. Antibiotics were given to 44 patients. The mean length of hospitalization was $12.5 \pm 2.9$ days. As expected, lung function variables and $\mathrm{PaO}_{2}$ improved significantly along with clinical recovery of the patients by the time of discharge (Table I).

Sputum culture with PPMs was found in 17 patients (H. influenzae: eight patients, $S$. pneumoniae: five patients, $M$. catarrhalis: two patients, and $P$. aeruginosa: two patients). In 33 cases, sputum culture was negative or indicated bacteria of the normal respiratory flora only. In the remaining 12 patients, the obtained sputum was not considered as a representative bronchial sample.

\section{eCO measurements}

At exacerbation, the levels of eCO were significantly increased in smokers compared to exsmokers $(6.0$ [2.0-9.5] versus 1.0 [1.0-2.0] ppm, $p<0.001)$. Similarly, eCO concentrations were higher in smokers after treatment (7.0 [2.0-12.5] versus $1.0[1.0-2.0] \mathrm{ppm}, p<0.001)$ (Fig. 2). No significant differences were detected between eCO levels at exacerbation and after treatment $(p>0.05)$, irrespective of patients' smoking status. The power of the study was $97.6 \%$ to detect a standardized difference in eCO between the smoker patients at exacerbation and after treatment. Patients receiving inhaled corticosteroids (ICS) had slightly reduced the eCO levels compared with those not taking ICS at admission, but the difference was not significant (data not shown).

To further explore the potential clinical utility of eCO measurements, patients with AECOPD were stratified by bacterial culture results at exacerbation. However, eCO levels were similar between the bacterial and non-bacterial exacerbations irrespective of whether the subjects were smokers or ex-smokers (smokers: 9.0 [4.0-11.5] versus 6.0 [2.0-9.5] ppm, $p>0.05$; ex-smokers: $2.0[2.0-3.0]$ versus $1.0[0.5-2.0] \mathrm{ppm}, p>0.05$ ).

\section{$\mathrm{HbCO}$ measurements}

In agreement with the findings in $\mathrm{eCO}$, the levels of $\mathrm{HbCO}$ in the blood were also elevated in smoker patients compared to ex-smoker subjects, both at exacerbation and discharge (Table I). HbCO levels at exacerbation and after treatment were similar. 


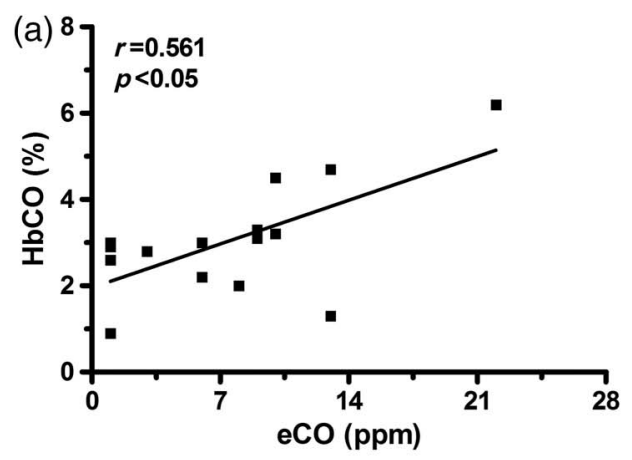

Fig. 3. Correlation between exhaled carbon monoxide (eCO) and blood carboxyhemoglobin (HbCO) concentrations at the time of an acute exacerbation (a) and after hospital treatment (b) assessed in a subset of current smoker patients $(n=15)$

\section{Correlations}

In the subgroup of current smoker patients $(n=15)$, a significant correlation was observed between $\mathrm{eCO}$ and $\mathrm{HbCO}$ concentrations, both at exacerbation $(r=0.561, p<0.05)$ and discharge $(r=0.574, p<0.05)$ (Fig. 3). In the subgroup of ex-smoker subjects $(n=19)$, eCO and $\mathrm{HbCO}$ levels did not correlate (data not shown). No significant correlations were observed between the eCO values and clinical variables, lung function, or blood gas parameters (data not shown).

\section{Discussion}

The aim of this study was to assess whether common treatment with corticosteroids and bronchodilators modifies eCO concentrations in patients hospitalized with AECOPD. We have observed no change in eCO during hospitalization indicating that the treatment of or recovery from an exacerbation is not mirrored in eCO levels in patients with COPD. This is reminiscent to some earlier findings where no difference in eCO was found in stable COPD patients with and without corticosteroid treatments (20). Similarly, in subjects with asthma, there was no difference in eCO between patients who were taking ICS and those who were not (22). Moreover, the expression of different heme-oxygenase isoenzymes responsible, at least in part, for the biosynthesis of $\mathrm{CO}$ in the airways may also be independent of ICS therapy in asthmatic patients (17). Importantly, our study was sufficiently powered to detect a clinically meaningful change in eCO between the patients before and after treatment. Thus, contrary to early expectations and some promising findings in CF (1) and asthma (30), eCO does not appear to be a useful biomarker to monitor inflammation and/or oxidative stress in patients with AECOPD.

We have also demonstrated that eCO concentrations are higher in current smoker patients compared to ex-smoker subjects, both at onset and after treatment of AECOPD. This finding agrees with the previous studies showing that smoker COPD patients have elevated eCO values compared to ex-smokers (18). Smoking one cigarette results in an approximately three-fold increase in eCO concentrations, and active smokers may have up to 20-25 ppm CO in their exhaled breath (14). In our study, smokers had slightly lower eCO levels than these values, which could be explained by reduced smoking frequency of the patients prior hospitalization due to their poor clinical status and severe dyspnea. 
Endogenously produced $\mathrm{CO}$ diffuses to the blood where it is transported by hemoglobin in the form of $\mathrm{HbCO}$ and is released to the alveolar space during gas exchange $(9,25)$. Therefore, the measurement of blood $\mathrm{HbCO}$ concentration may also be a marker to monitor the severity of local and/or systemic oxidative stress in a wide variety of pulmonary and extrapulmonary diseases. In line with this view, Yasuda et al. have recently demonstrated that blood $\mathrm{HbCO}$ concentrations in arteries and peripheral veins are increased in patients with asthma, COPD, and pneumonia compared to healthy subjects (31). Moreover, they observed a close correlation between $\mathrm{eCO}$ and $\mathrm{HbCO}$ levels in these conditions. Interestingly, in patients with $\mathrm{COPD}, \mathrm{HbCO}$ correlated with eCO only at moderate stages of COPD severity (GOLD stages II and III) but not at advanced stage (GOLD stage IV) (32).

In our study, we have shown that $\mathrm{HbCO}$ levels are increased in smokers compared to exsmokers, both at exacerbation and after treatment. Moreover, $\mathrm{HbCO}$ and eCO levels showed a significant correlation in smokers. Interestingly, Wald et al. found a tighter correlation between eCO and $\mathrm{HbCO}$ values compared to our data (0.97 versus 0.56 ) (28). However, this study (28) was performed on a large cohort of healthy smokers and eCO was assessed by a different technique. In line with our findings about eCO, treatment of AECOPD did not modify blood $\mathrm{HbCO}$ concentrations either. Thus, like on eCO levels, smoking but not disease activity (exacerbation versus convalescence) has a major impact on blood $\mathrm{HbCO}$ concentrations.

Although the etiology of AECOPD is heterogeneous, bacterial infections may play a significant role in the development of AECOPD (4). Since eCO has been widely implicated as a biomarker of respiratory infections $(5,19,29)$, we investigated whether eCO concentrations differ between bacterial and non-bacterial AECOPD. This is an important issue, since on clinical grounds it is difficult to predict a bacterial course of AECOPD which requires antibiotic treatment. Nonetheless, eCO levels were comparable between bacterial and nonbacterial exacerbations indicating that eCO cannot serve as a biomarker to identify those cases where a bacterial agent is likely to contribute to AECOPD. We are aware that AECOPD may be triggered by viral infections as well; however, for the lack of available data, this analysis could not be carried out.

It has been shown that both eCO and $\mathrm{HbCO}$ levels change toward the normal values in smokers within 12-24 h after temporary cessation of smoking $(15,26)$. In our study, however, these marker levels remained elevated by the time of hospital discharge. Since exsmokers exhibited almost normal eCO concentrations, it is not likely that persistent airway inflammation could account for this finding. We speculate that although smoking is prohibited in our hospital, some patients continued to smoke during treatment, which could have an effect on our results. Indeed, as also indicated in the literature, the compliance of smokers with hospital no-smoking policies is often poor (24).

It should be noted that eCO levels in ex-smoker COPD patients were in the range of theoretical sensitivity of the detection method. In contrast, eCO values in smokers were markedly higher compared to these values. Thus, although marker levels in ex-smoker subjects should be interpreted with caution, smokers can be reliably discriminated from exsmokers using this device. Consequently, this eCO measurement methodology is widely accepted by experts on this field of research $(12,13,21,26,29-32)$.

Of importance, we found no correlation between the eCO levels and lung function parameters in our study. Similarly, in a population survey of smokers from the Copenhagen Heart Study, eCO values were found to have no correlation with lung function or lung function decline in smokers either (8). Other authors have also failed to 
observe any association between eCO and lung function indices in stable patients with COPD (18).

In conclusion, although the measurement of eCO is feasible in patients with AECOPD requiring hospitalization, the clinical applicability of the test to monitor airway inflammation and/or oxidative stress during recovery from an exacerbation is limited. Similarly, eCO measurement does not appear to be useful to identify the cases of AECOPD with bacterial etiology either.

\section{Acknowledgements}

The authors would like to thank M. Mikoss and J. Hernadi (National Koranyi Institute of TB and Pulmonology) for their assistance in eCO measurements. The study was supported by the Hungarian Respiratory Foundation and by the Hungarian National Scientific Foundation (OTKA K83338). Dr. B. Antus is a recipient of Bolyai Janos Scholarship of the Hungarian Academy of Sciences.

\section{REFERENCES}

1. Antuni JD, Kharitonov SA, Hughes D, Hodson ME, Barnes PJ: Increase in exhaled carbon monoxide during exacerbation of cystic fibrosis. Thorax 55, 138-142 (2000)

2. Antus B, Barta I, Kullmann T, Lazar Z, Valyon M, Horvath I, Csiszer E: Assessment of exhaled breath condensate $\mathrm{pH}$ in exacerbations of asthma and chronic obstructive pulmonary disease: a longitudinal study. Am. J. Respir. Crit. Care Med. 182, 1492-1497 (2010)

3. Barbour AG, Hirsch CM, Ghalyanchi Langeroudi A, Meinardi S, Lewis ER, Estabragh AS, Blake DR: Elevated carbon monoxide in the exhaled breath of mice during a systemic bacterial infection. PLoS One 8, e69802 (2013)

4. Beasley V, Joshi PV, Singanayagam A, Molyneaux PL, Johnston SL, Mallia P: Lung microbiology and exacerbations in COPD. Int. J. Chron. Obstruct. Pulmon. Dis. 7, 555-569 (2012)

5. Biernacki WA, Kharitonov SA, Barnes PJ: Exhaled carbon monoxide in patients with lower respiratory tract infection. Respir. Med. 93, 1003-1005 (2001)

6. Carpagnano GE, Kharitonov SA, Foschino-Barbaro MP, Resta O, Gramiccioni E, Barnes PJ: Increased inflammatory markers in the exhaled breath condensate of cigarette smokers. Eur. Respir. J. 21, 589-593 (2003)

7. Deveci SE, Deveci F, Açik Y, Ozan AT: The measurement of exhaled carbon monoxide in healthy smokers and non-smokers. Respir. Med. 98, 551-556 (2004)

8. Fabricius P, Scharling H, Løkke A, Vestbo J, Lange P: Exhaled CO, a predictor of lung function? Respir. Med. 101, 581-586 (2007)

9. Gajdócsy R, Horváth I: Exhaled carbon monoxide in airway diseases: from research findings to clinical relevance. J. Breath Res. 4, 047102 (2010)

10. Garcia LS, Isenberg HD (2010): Clinical Microbiology Procedures Handbook. 3rd ed. ASM Press, Washington, DC

11. Hillas G, Loukides S, Kostikas K, Bakakos P: Biomarkers obtained by non-invasive methods in patients with COPD: where do we stand, what do we expect? Curr. Med. Chem. 16, 2824-2838 (2009)

12. Horvath I, Donnelly LE, Kiss A, Paredi P, Kharitonov SA, Barnes PJ: Raised levels of eCO are associated with an increased expression of heme-oxygenase-1 in airway macrophags of asthma: a new marker of oxidative stress. Thorax 53, 668-672 (1998)

13. Horvath I, Loukides S, Wodehouse T, Kharitonov SA, Cole PJ, Barnes PJ: Increased levels of carbon monoxide in bronchiectasis: a new marker of oxidative stress. Thorax 53, 867-870 (1998)

14. Hung J, Lin CH, Wang JD, Chan CC: Exhaled carbon monoxide level as an indicator of cigarette consumption in a workplace cessation program in Taiwan. J. Formos. Med. Assoc. 105, 210-213 (2006)

15. Kambam JR, Chen LH, Hyman SA: Effect of short-term smoking halt on carboxyhemoglobin levels and P50 values. Anesth. Analg. 65, 1186-1188 (1986)

16. Kirkham PA, Barnes PJ: Oxidative stress in COPD. Chest 144, 266-273 (2013)

17. Lim S, Groneberg D, Fischer A, Oates T, Caramori G, Mattos W, Adcock I, Barnes PJ, Chung KF: Expression of heme oxygenase isoenzymes 1 and 2 in normal and asthmatic airways: effects of inhaled corticosteroids. Am. J.

Respir. Crit. Care Med. 162, 1912-1918 (2000) 
18. Montuschi P, Kharitonov SA, Barnes PJ: Exhaled carbon monoxide and nitric oxide in COPD. Chest 120, 496-501 (2001)

19. Morimatsu H, Takahashi T, Matsusaki T, Hayashi M, Matsumi J, Shimizu H, Matsumi M, Morita K: An increase in exhaled CO concentration in systemic inflammation/sepsis. J. Breath Res. 4, 047103 (2010)

20. Paredi P, Kharitonov SA, Leak D, Ward S, Cramer D, Barnes PJ: Exhaled ethane, a marker of lipid peroxidation, is elevated in chronic obstructive pulmonary disease. Am. J. Respir. Crit. Care Med. 162, 369-373 (2000)

21. Paredi P, Shah PL, Montuschi P, Sullivan P, Hodson ME, Kharitonov SA, Barnes PJ: Increased carbon monoxide in exhaled air of patients with cystic fibrosis. Thorax 54, 917-920 (1999)

22. Pogson ZE, Antoniak MD, Mckeever TM, Lewis SA, Britton JR, Fogarty AW: Exhaled carbon monoxide in asthmatic adults with bronchial reactivity: a prospective study. J. Asthma 46, 665-669 (2009)

23. Rabe KF, Hurd S, Anzueto A, Barnes PJ, Buist SA, Calverley P, Fukuchi Y, Jenkins C, Rodriguez-Roisin R, van Weel C, Zielinski J: Global strategy for the diagnosis, management, and prevention of chronic obstructive pulmonary disease: GOLD executive summary. Am. J. Respir. Crit. Care Med. 176, 532-555 (2007)

24. Rigotti NA, Arnsten JH, McKool KM, Wood-Reid KM, Pasternak RC, Singer DE: Smoking by patients in a smoke-free hospital: prevalence, predictors, and implications. Prev. Med. 31, 159-166 (2000)

25. Ryter SW, Choi AM: Carbon monoxide in exhaled breath testing and therapeutics. J. Breath Res. 7, 017111 (2013)

26. Sandberg A, Sköld CM, Grunewald J, Eklund A, Wheelock ÅM: Assessing recent smoking status by measuring exhaled carbon monoxide levels. PLoS One 6, e28864 (2011)

27. van der Valk P, Monninkhof E, van der Palen J, Zielhuis G, van Herwaarden C, Hendrix R: Clinical predictors of bacterial involvement in exacerbations of chronic obstructive pulmonary disease. Clin. Infect. Dis. 39, 980-986 (2004)

28. Wald NJ, Idle M, Boreham J, Bailey A: Carbon monoxide in breath in relation to smoking and carboxyhaemoglobin levels. Thorax 36, 366-369 (1981)

29. Yamaya M, Sekizawa K, Ishizuka S, Monma M, Mizuta K, Sasaki H: Increased carbon monoxide in exhaled air of subjects with upper respiratory tract infections. Am. J. Respir. Crit. Care Med. 158, 311-314 (1998)

30. Yamaya M, Sekizawa K, Ishizuka S, Monma M, Sasaki H: Exhaled carbon monoxide levels during treatment of acute asthma. Eur. Respir. J. 13, 757-760 (1999)

31. Yasuda H, Sasaki T, Yamaya M, Ebihara S, Maruyama M, Kanda A, Sasaki H: Increased arteriovenous carboxyhemoglobin differences in patients with inflammatory pulmonary diseases. Chest 125, 2160-2168 (2004)

32. Yasuda H, Yamaya M, Nakayama K, Ebihara S, Sasaki T, Okinaga S, Inoue D, Asada M, Nemoto M, Sasaki H: Increased arterial carboxyhemoglobin concentrations in chronic obstructive pulmonary disease. Am. J. Respir. Crit. Care Med. 171, 1246-1251 (2005) 